\title{
Categorização de blogs escritos por cientistas: uma proposta
}

\section{Categorization of blogs written by scientists: a proposal}

\author{
Isaltina Gomes \\ Doutora em linguística pela Universidade Federal de Pernambuco. Pesquisadora do Cnpq e docente do Programa de Pós- \\ Graduação em Comunicação da Universidade Federal de Pernambuco (UFPE). \\ <isaltina@gmail.com>

\section{Natalia Flores} \\ Mestre em Comunicação pela Universidade Federal de Santa Maria. Doutora em Comunicação na Universidade Federal de \\ Pernambuco (UFPE) \\ $<$ nataliflores@gmail.com>
}

\section{RESUMO}

Apresenta-se uma proposta de categorização dos blogs escritos por cientistas, a partir da análise quantitativa de 1.329 posts de 43 blogs. A análise toma como parâmetros as seguintes características: função comunicacional, papel dos participantes e configuração discursiva. Propõe-se a existência de duas categorias de enunciação presentes nessas discursividades: do Cientista blogueiro divulgador, marcado por estratégias enunciativas de distanciamento e registros informativos (dividindo-se nas subcategorias de matéria de DC, agenda/mural) e do Cientista blogueiro protagonista, marcado por estratégias enunciativas de envolvimento e registros opinativos (subcategorias de agenda/vitrine, crítica, diário e pessoal). A emergência da categoria Cientista blogueiro protagonista em $75 \%$ do corpus permite classificar o blog como um espaço de expressão do self por meio da construção de uma imagem opinativa e subjetiva do cientista blogueiro.

Palavras-chave: Blogs de cientistas. Estratégias enunciativas. Divulgação científica.

\begin{abstract}
It presents a proposal of categorization of blogs written by scientists from the quantitative analysis of 1,329 posts of 43 blogs. The analysis takes as parameters the following characteristics that conform communicative activity: communication function, role of participants and discursive configuration. It proposes the existence of two enunciation categories present in these discourses: Scientist blogger as a spreader, marked by enunciative strategies of distancing and informative records (subcategories of article of science popularization and notice board) and Scientist blogger as a protagonist, marked by enunciative strategies of involvement and opinion records (subcategories of showcase, critics, diary and personal). The emergence of Scientist protagonist category in $75 \%$ of the corpus allows us to classify the blog as a self expression of space through the construction of an opinionated and subjective image of the scientist blogger.
\end{abstract}

Keywords: Scientists' blogs. Enunciative strategies. Science popularization.

\section{Introdução}

Nos últimos anos, houve um crescimento progressivo de estudos sobre blogs acadêmicos ou blogs de ciência, dispositivos que passaram a se estabelecer como prática social da comunidade científica. Num primeiro momento, esses estudos detiveram-se na descrição e contextualização do 
fenômeno de emergência desses espaços, investigando as motivações dos cientistas para blogar (Kjellberg, 2010) assim como o seu lugar social dentro do universo da comunidade científica, como uma prática complementar à prática tradicional acadêmica (Gregg, 2006). Dentre os estudos brasileiros, temos o de Porto (2010), que realizou um mapeamento dos lugares de disseminação e divulgação científica na internet, apontando os blogs como canais promissores para o fortalecimento de uma cultura científica brasileira.

Num segundo momento, tem-se um direcionamento dos estudos sobre blogs escritos por cientistas para análises empíricas que permitem um maior detalhamento desses espaços. Alguns estudos qualitativos começam a ser empreendidos, como o de Kouper (2010), que investigou o conteúdo de 11 blogs quanto às fontes de informação utilizadas, os tópicos e os modos de comunicação e participação de blogueiros e leitores; e o de Fagundes (2014), que se deteve na análise das estratégias de comunicação utilizadas pelos cientistas blogueiros da comunidade ScienceBlogs Brasil para atrair seus leitores. Nenhum desses estudos, no entanto, fornece uma abordagem ao mesmo tempo discursiva e quantitativa sobre os blogs que operam sobre esse funcionamento.

Neste artigo, propomos um estudo do conteúdo dos blogs escritos por cientistas brasileiros, resultado da nossa pesquisa de doutorado, que tem como tema os espaços de enunciação de cientistas blogueiros. A partir de um aporte teórico dos estudos da linguagem e do discurso, analisamos um total de 1.329 posts de 43 blogs escritos por pesquisadores, demarcando características que conformam a sua atividade comunicativa, como as estratégias enunciativas, os registros discursivos e as funções comunicacionais. Formulamos, então, uma proposta de categorização do conteúdo dos blogs, que será apresentada a seguir.

\section{Funções comunicativas e estratégias enunciativas}

$\mathrm{O}$ arcabouço teórico utilizado nesta pesquisa parte das premissas das teorias da Análise do Discurso e dos estudos da linguagem, principalmente dos conceitos de função comunicacional e estratégias enunciativas, utilizadas na observação e categorização do corpus. Baseada nas leituras de Maingueneau (2014), a função comunicacional é entendida como um elemento que se desdobra nas funções social e discursiva do enunciado que visa uma ação. O discurso é, então, tido como performativo, pois pretende agir sobre uma situação, transformando-a. O cientista blogueiro, por exemplo, utilizaria o blog 
para desempenhar determinadas funções comunicacionais que podem ser localizadas no modo como o enunciador conforma o seu enunciado.

Percebe-se que a função comunicativa tem papel preponderante sobre os outros elementos do discurso, pois é a partir dela que se moldam o papel dos participantes e a configuração textual do enunciado. Escolher uma função comunicativa específica implica definir, primeiramente, papeis para os participantes comunicativos, que estabelecem entre si um contrato de comunicação regido por normas. No caso dos blogs, o contrato de comunicação envolveria um acordo implícito no qual o cientista blogueiro assume o papel de divulgar informações científicas e não científicas e, ao mesmo tempo, de expressar sua opinião. Esse contrato de comunicação é fundador do ato da linguagem, sendo que o interlocutor-destinatário do blog já adere previamente aos seus termos (Charaudeau, 1995).

As funções comunicativas assumidas pelo blogueiro também conformam as estratégias linguístico-discursivas escolhidas por ele para configurar o seu discurso, entre elas, as estratégias de enunciação e os registros linguísticos utilizados. As estratégias de enunciação ou enunciativas remetem à posição que o enunciador assume no seu enunciado, ora aproximando-se do que é dito, ora afastando-se. Em seus estudos, Chafe (1984; 1985 citado por Gomes, 2000) denomina-as de estratégias de distanciamento e de envolvimento que, segundo o autor, se encontrariam respectivamente presentes na escrita e na fala. Como atividade solitária, a escrita envolveria um distanciamento do enunciador, por meio de elementos como a voz passiva, no emprego de particípios e nas citações indiretas, entre outros elementos.

De outra maneira, sendo interativa, a fala traria um envolvimento do enunciador com o seu discurso, o que ocorreria de três modos "[...] envolvimento do falante com ele mesmo; auto-envolvimento do falante com o ouvinte, concernente à dinâmica da interação com o outro; e envolvimento do falante com o conteúdo, um compromisso pessoal com o assunto abordado" (Chafe, 1985, citado por Gomes, 2000, p. 154). Entre outros elementos, esses seriam, respectivamente, caracterizados pelo uso de pronomes pessoais e possessivos em 1 a pessoa e de expressões como "eu acho", "eu sei", "eu digo"; pela referência à $2^{\text {a }}$ pessoa por meio de marcadores conversacionais e por marcas textuais que expressem a relação do enunciador com o assunto, como partículas adverbiais modalizadoras, exclamações, etc.

As relações entre escrita e distanciamento propostas por Chafe encontram contraposições em estudos linguísticos, como os de Isaltina Gomes (2000). Apropriando-se da teorização do autor, a pesquisadora mostra que marcas 
relacionadas ao envolvimento podem também ser encontradas na escrita, embora em menor quantidade se comparada à produção oral. Sua análise de artigos e matérias de divulgação científica escritos por cientistas e jornalistas na revista Ciência Hoje revela que estratégias de envolvimento ocorrem nos dois tipos de texto, sendo que marcas de envolvimento com o conteúdo - como o discurso direto, o presente histórico e os advérbios - aparecem em maior quantidade.

Num segundo momento, prestamos atenção aos registros linguísticos presentes nos posts, os quais teriam relação à função comunicativa proposta pelo texto e à posição assumida pelo enunciador. Esses registros conformariam o discurso segundo elementos mais informativos - relacionadas a um posicionamento mais neutro e impessoal do enunciador - ou opinativos, que remeteriam a enunciações em que o enunciador assume uma posição argumentativa e, portanto, abrangeria estratégias de envolvimento.

Cabe salientarmos aqui que não analisamos os marcadores linguísticos de maneira fechada e estrita. Tendo em vista que a tendência geral do enunciador de blogs é a de personalizar seu texto utilizando marcadores subjetivos, como a primeira pessoa e modalizadores, acreditamos que a predominância desses elementos remete a um texto opinativo. Trata-se de empreender uma análise que leve em conta a complexidade da materialidade discursiva dos posts, combinando a localização de marcadores linguísticos à função comunicativa do post. Assim, podemos ter casos de posts nos quais aparecem marcadores subjetivos em textos que visam a disseminação de informações ou o anúncio de eventos - embora eles não predominem no texto. Nesses casos, optamos pela função comunicativa como critério de categorização, pois entendemos que ela predomina sobre os outros elementos.

\section{Proposta de categorização dos blogs}

A nossa análise quantitativa debruçou-se sobre um corpus composto por 1.329 posts, de 43 blogs escritos por pesquisadores, selecionados num aleatório de um ano, de janeiro a dezembro de 2013. O recorte do corpus seguiu os seguintes critérios: a) blogs de pesquisadores e estudantes de pós-graduação brasileiros, b) atualizados frequentemente e c) que produzissem conteúdo sobre ciência. Por meio de pesquisas nos sites Anel de Blogs Científicos e Science Blogs Brasil, foram selecionados 43 blogs, 19 da área das Ciências da Vida, 10 das Ciências Exatas e Tecnológicas e 14 das Ciências Humanas. 
No quadro 1, apresentamos a proposta de categorização dos blogs escritos por pesquisadores:

\section{Quadro 1: Proposta de categorização do conteúdo dos blogs}

\begin{tabular}{|c|c|c|c|}
\hline Categoria & Subcategoria & Funçào & Registros \\
\hline $\begin{array}{l}\text { Cientista } \\
\text { blogueiro } \\
\text { divulgador }\end{array}$ & $\begin{array}{l}\text { Materia de } \\
\text { divulgaçaso } \\
\text { clentifica } \\
\text { (MDC) }\end{array}$ & $\begin{array}{l}\text { Divulgar } \\
\text { pesquisas } \\
\text { cientificas o } \\
\text { intormapoles } \\
\text { sobre cidncia }\end{array}$ & Informativo \\
\hline $\begin{array}{l}\text { Enunciador nå e e } \\
\text { centro do } \\
\text { enunciado } \\
\text { (estrategiss de } \\
\text { distanciamento) }\end{array}$ & Agenda/mural & $\begin{array}{l}\text { Anunciar } \\
\text { eventos } \\
\text { cientificos ou } \\
\text { clipping de } \\
\text { noticias: } \\
\text { Fomecer dicas } \\
\text { acs } \\
\text { pesquispdores }\end{array}$ & \\
\hline \multirow{4}{*}{$\begin{array}{l}\text { Cientista } \\
\text { blogueiro } \\
\text { protagonista } \\
\text { Enunciador b o } \\
\text { centro do } \\
\text { enunciado } \\
\text { (estratbgias de } \\
\text { envolvimento) }\end{array}$} & Agenda/vitrine & $\begin{array}{l}\text { Dar visibilidade } \\
\text { ao cientista } \\
\text { blogueiro ou ao } \\
\text { grupo de } \\
\text { pesquisa } \\
\text { (coletivo ou } \\
\text { individual) }\end{array}$ & \\
\hline & $\begin{array}{l}\text { Critica } \\
\text { (C) }\end{array}$ & $\begin{array}{l}\text { Criscar o } \\
\text { sistema } \\
\text { cientifico, } \\
\text { educativo ou as } \\
\text { pesquisas } \\
\text { (sujeito- } \\
\text { instifucional) }\end{array}$ & \multirow[t]{3}{*}{ Opinativo } \\
\hline & $\begin{array}{l}\text { Diário } \\
\text { (D) }\end{array}$ & $\begin{array}{l}\text { Relletir sobre a } \\
\text { vida em } \\
\text { laboratorio e } \\
\text { outras questðes } \\
\text { relacionadas a } \\
\text { prática cientifica } \\
\text { ou a ciência } \\
\text { (sujeito- } \\
\text { pesquispdor) }\end{array}$ & \\
\hline & $\begin{array}{l}\text { Pessoal } \\
\text { (P) }\end{array}$ & $\begin{array}{l}\text { Refletir sobre a } \\
\text { vida pessoal e } \\
\text { outros assumos } \\
\text { nâo cientificos }\end{array}$ & \\
\hline
\end{tabular}

Fonte: as autoras.

Tendo a posição do enunciador como parâmetro central, no Gráfico 1, dividimos os posts analisados em duas categorias: A) o enunciador não é o centro do enunciado (Cientista blogueiro divulgador) e B) o enunciador é o centro do enunciado (Cientista blogueiro protagonista). Elas remetem, respectivamente, às estratégias de distanciamento e de envolvimento de Chafe e produzem efeitos de sentido distintos no discurso. No primeiro caso, predominam marcadores linguísticos de voz passiva e particípios, enquanto que, no segundo caso, 
predominam marcadores linguísticos subjetivos, no qual o enunciador assume a sua fala.

Essas categorias ainda podem ser divididas nas seguintes subcategorias, nomeadas de acordo com sua função comunicativa: (1) matéria de DC, (2) agenda/mural, (3) agenda/vitrine, (4) crítica, (5) diário e (6) pessoal. As estratégias de distanciamento do enunciador configurariam funções comunicativas de anunciar eventos científicos e divulgar pesquisas científicas e informações sobre ciência, moldando-se segundo registros informativos. De outro modo, as estratégias de envolvimento relacionam-se a posts cuja função comunicativa é a de refletir sobre o campo científico, o papel social de cientista e outros assuntos e utilizam-se de registros opinativos.

A partir de um tratamento estatístico, chegou-se à seguinte recorrência das categorias e subcategorias no corpus (Gráfico 1):

Gráfico 1: Recorrência das categorias nos blogs (em porcentagem)

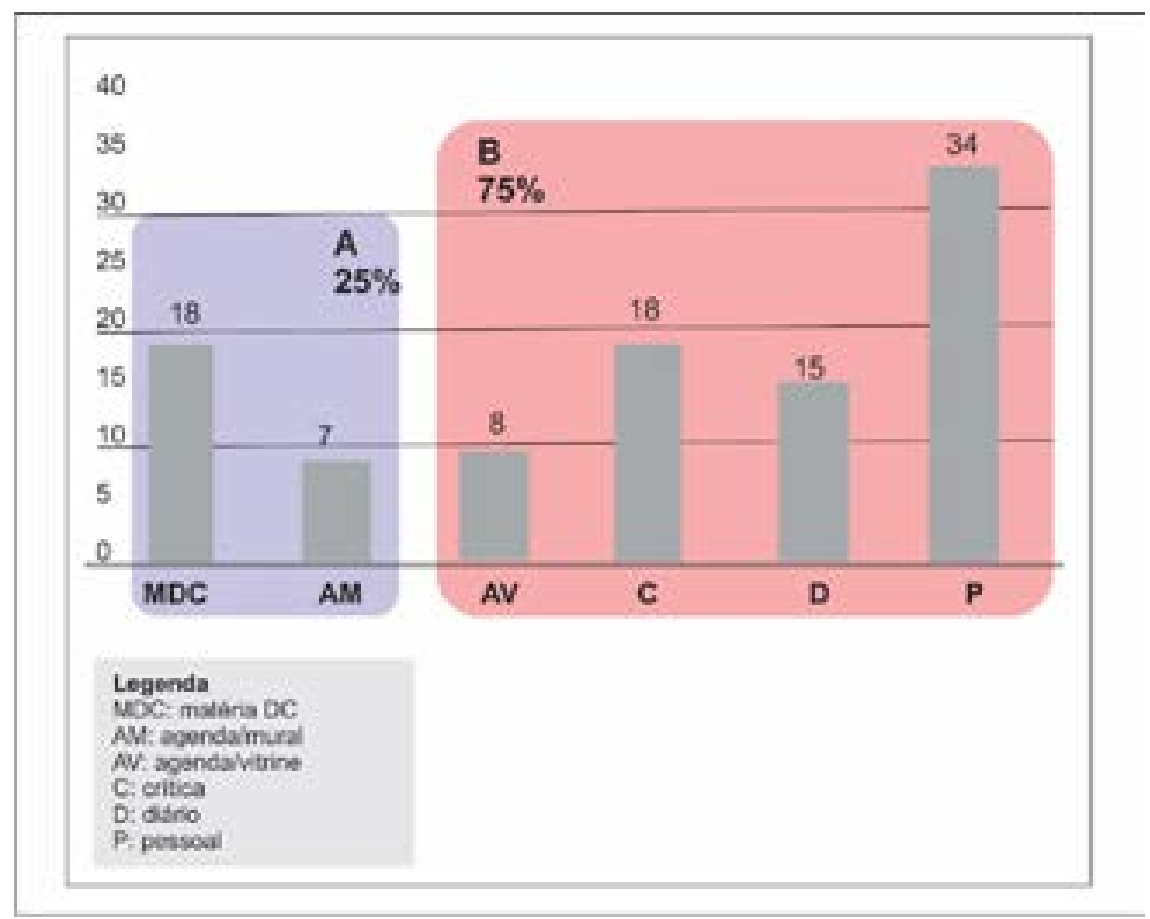

Fonte: as autoras.

Observa-se no gráfico a predominância da categoria Cientista blogueiro protagonista (B) (75\%) em detrimento da categoria de Cientista blogueiro divulgador $(A)$, sugerindo que a maioria dos posts analisados assumem o enunciadorcomo centro do enunciado, recorrendo a estratégias deenvolvimento e a registros opinativos. Essa configuração discursiva permite compreendermos 
os blogs escritos por pesquisadores como espaços onde o cientista blogueiro demarca sua opinião sobre os assuntos publicados. Essa característica é reforçada pelo fato da subcategoria pessoal aparecer como a mais expressiva no corpus, representando $34 \%$ do seu conteúdo, seguida pelas subcategorias de crítica (18\%) e diário (15\%). A ocorrência de $15 \%$ da subcategoria matéria de DC também demonstra uma preocupação na disseminação de assuntos científicos pelo blogueiro, além da reflexão e crítica sobre conteúdos não científicos e sobre a práxis científica.

Os dados também permitem observarmos a recorrência das categorias Cientista blogueiro divulgador (A) e Cientista blogueiro protagonista (B) nos blogs de cada área de pesquisa (gráfico 2):

\section{- Gráfico 2: Categorias A e B X Área científica}

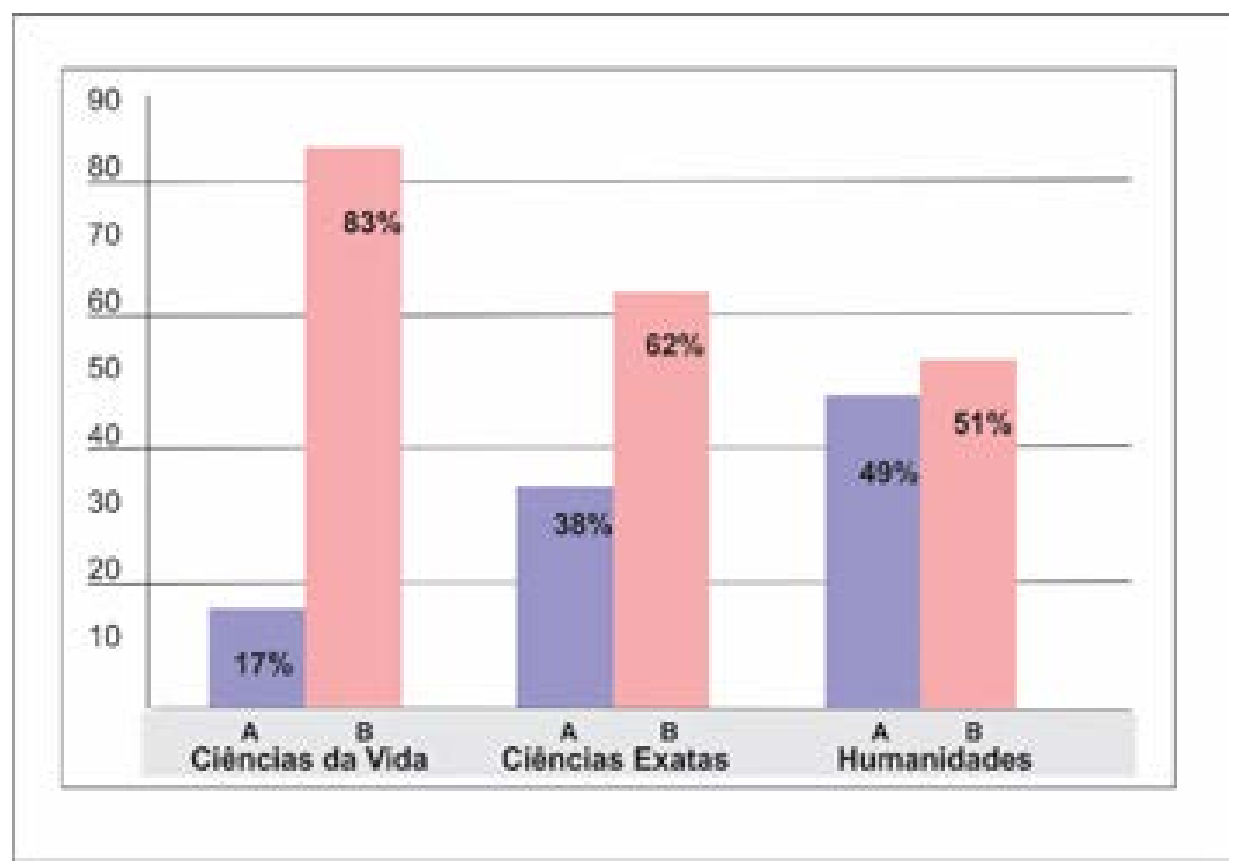

Fonte: as autoras.

Segundo o gráfico, posts da categoria B, de envolvimento, são maioria nos blogs das Ciências da Vida (somando de $83 \%$ de seus posts) e representam mais da metade dos posts nos blogs das Ciências Exatas. As categorias A e B somente se equiparam nos blogs das Ciências Humanas, onde se dá mais espaço para as subcategorias informativas em comparação aos blogs de outras áreas.

Pode-se presumir que a grande quantidade de textos em que 0 enunciador assume estratégias de envolvimento em blogs das ciências biológicas contrapõem-se às características desta área científica, onde a 
linguagem científica sofre um processo de escamoteação sistemática da enunciação (Jurdant, 2006a; 2006b). Diferentemente deste processo, no qual se impõe um distanciamento entre a enunciação e o enunciado e um apagamento do sujeito enunciador, pode-se observar nos blogs destas disciplinas uma preponderância de marcas enunciativas do blogueiro e uma aproximação entre situação enunciativa e enunciado. Essa configuração indica, então, que esses dispositivos são formas alternativas de construção de si encontradas por esses cientistas blogueiros.

Se observarmos as categorias enunciativas e as subcategorias propostas no quadro 1, percebemos que a variabilidade de configuração discursiva se encontra nas suas subcategorias, que moldam os posts de acordo com funções comunicativas diversas. Assim, comoobjetivo de descrevermais detalhadamente o corpus, explicitamos a seguir as características das subcategorias matéria de DC, agenda/mural, agenda/vitrine, diário, crítica e pessoal.

\section{Estratégias de distanciamento}

\section{Matéria de DC (MDC)}

A subcategoria de matéria de DC define-sesegundo a função de divulgação de informações sobre a área de conhecimento do cientista blogueiro. Os seus textos possuem registros informativos que pretendem explicar a realidade por meio do ponto de vista científico. Neles, o enunciador assume o papel de informar e ensinar o coenunciador sobre conteúdos científicos, relacionando-os com o cotidiano do leitor. Esse conteúdo é colocado no lugar central no enunciado, ao mesmo tempo em que o enunciador assume uma posição secundária, através de estratégias de distanciamento do seu texto.

O trabalho de linguagem feito nesta categoria aproxima-se do que Gomes (2000) denomina de matéria de DC, utilizada para nomear os eventos textuais desenvolvidos por jornalistas na revista Ciência Hoje. Ainda que tenham algumas diferenças quanto ao enunciador - que nos blogs é cientista - e a estrutura do texto - que não segue formalmente as características de uma matéria jornalística, com abertura, contextualização, metodologia e perspectivas - os textos dos blogs também tem o propósito de divulgar resultados de pesquisas científicas, preocupam-se com a recodificação da linguagem científica e tem como público pessoas que não tem conhecimento específico sobre a área de pesquisa específica divulgada, características típicas da divulgação científica (Calvo Hernando, 1992; Bueno, 2009). 
Os textos da subcategoria matéria de DC conformam-se numa estrutura descritiva que aborda objetos de pesquisa de uma área científica em particular, discussões teóricas sobre conceitos científicos, apresentação de resultados de pesquisa de algum estudo recente ou projetos de pesquisa em execução. Nos blogs das Ciências da Vida, os posts abordam fenômenos biológicos, trazendo explicações sobre plantas, animais, etc. Esse é o caso do post da Figura 1, que faz parte de uma série do blog "Ciência à Bessa" sobre estratégias de camuflagem de animais (Figura 1). Nos blogs das Ciências Naturais e Exatas e das Ciências Humanas, aparecem textos sobre discussões e observações de fenômenos naturais e sociais.

\section{Figura 1: Post exemplifica subcategoria de matéria de DC}
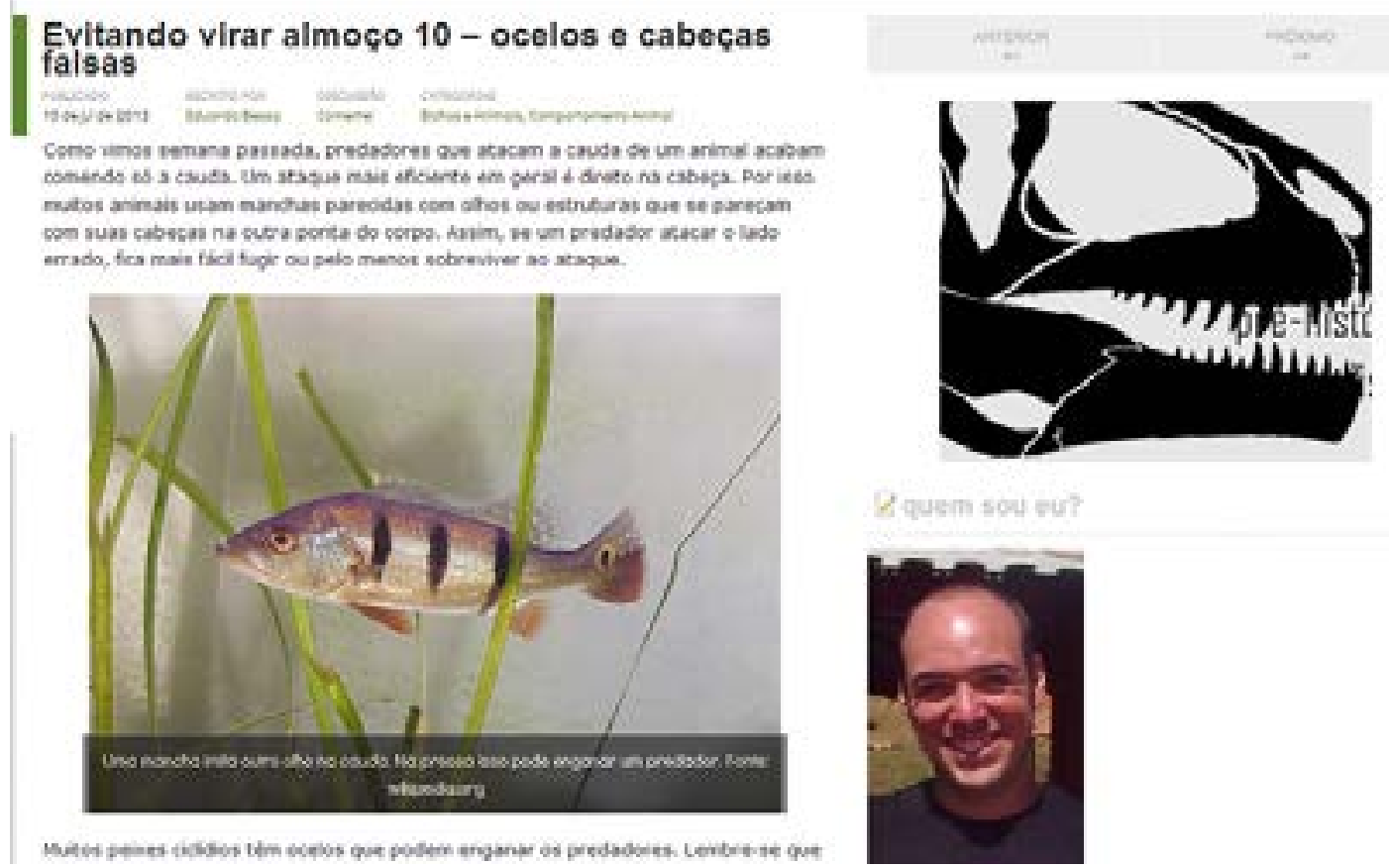

Fonte:<http://scienceblogs.com.br/bessa/2013/07/evitando-virar-almoco-10-ocelos-e-cabecas-falsas $>$

Os textos trazem referências bibliográficas de livros ou artigos científicos no final do post. Eles geralmente possuem um selo do Research Blogging que agrega seu conteúdo a um site, tornando-os visíveis a uma parcela maior de pessoas que buscam conteúdos sobre ciência e artigos científicos.

Também entram na subcategoria de matéria de DC textos baseados em estudos científicos que explicam e interpretam aspectos da realidade e do cotidiano das pessoas por meio do viés científico. O olhar científico sobre a realidade pode ser tanto do cientista blogueiro como de outros cientistas que 
ele insere no seu dizer, por meio de entrevistas e citações de outros estudos. A inserção do outro mostra-nos que a maioria dos textos dessa categoria trata de estudos e teorias de outros pesquisadores, sendo que são poucos os que explicitam os resultados de pesquisas pontuais dos cientistas blogueiros e seus grupos de pesquisa.

\section{Agenda/mural}

A subcategoria de agenda/mural tem como função comunicativa o anúncio de eventos científicos e outros assuntos relativos à comunidade científica. Assim como a subcategoria anterior, ela pertence à categoria de estratégias de distanciamento (categoria Cientista blogueiro divulgador) e utiliza registros informativos com poucas marcas da presença do enunciador no texto, pois não tem como função principal a demarcação da opinião desse sujeito. Seus textos são curtos e se assemelham aos enunciados presentes em murais de departamentos de ensino e pesquisa e laboratórios. Trata-se de espaços onde são divulgadas informações sobre a vida acadêmica, como palestras, concursos culturais, horários de disciplinas, entre outros.

Nos blogs, a subcategoria agenda/mural remete a posts que fornecem informações aos leitores sobre as atividades e palestras promovidas pelos cursos de pós-graduação no Brasil, promovendo e cobrindo eventos científicos de programas de pós-graduação e livros de suas áreas de pesquisa. Eles promovem o evento antes de ele acontecer ou trazem conteúdos do que foi discutido em eventos que já ocorreram. Os posts de divulgação geralmente disponibilizam o cartaz ou folheto de programação, junto com um pequeno texto com a descrição do evento científico (figura 2).

A subcategoria agenda/mural também reúne posts com podcasts ou outros materiais, como artigos científicos, clipping de notícias e links. Os textos são curtos e, em algumas vezes, possuem a estrutura de uma lista de itens indicados pelo blogueiro - como no caso dos links. Embora as marcas da presença do blogueiro no texto sejam sutis, esses textos também possuem marcas de personalização características do suporte blog. A seleção de links e de eventos científicos, por exemplo, já configuram um índice de personalização do texto, já que essa seleção se baseia em elementos que o blogueiro considera interessantes. 
- Figura 2: Post exemplifica subcategoria de agenda/mural

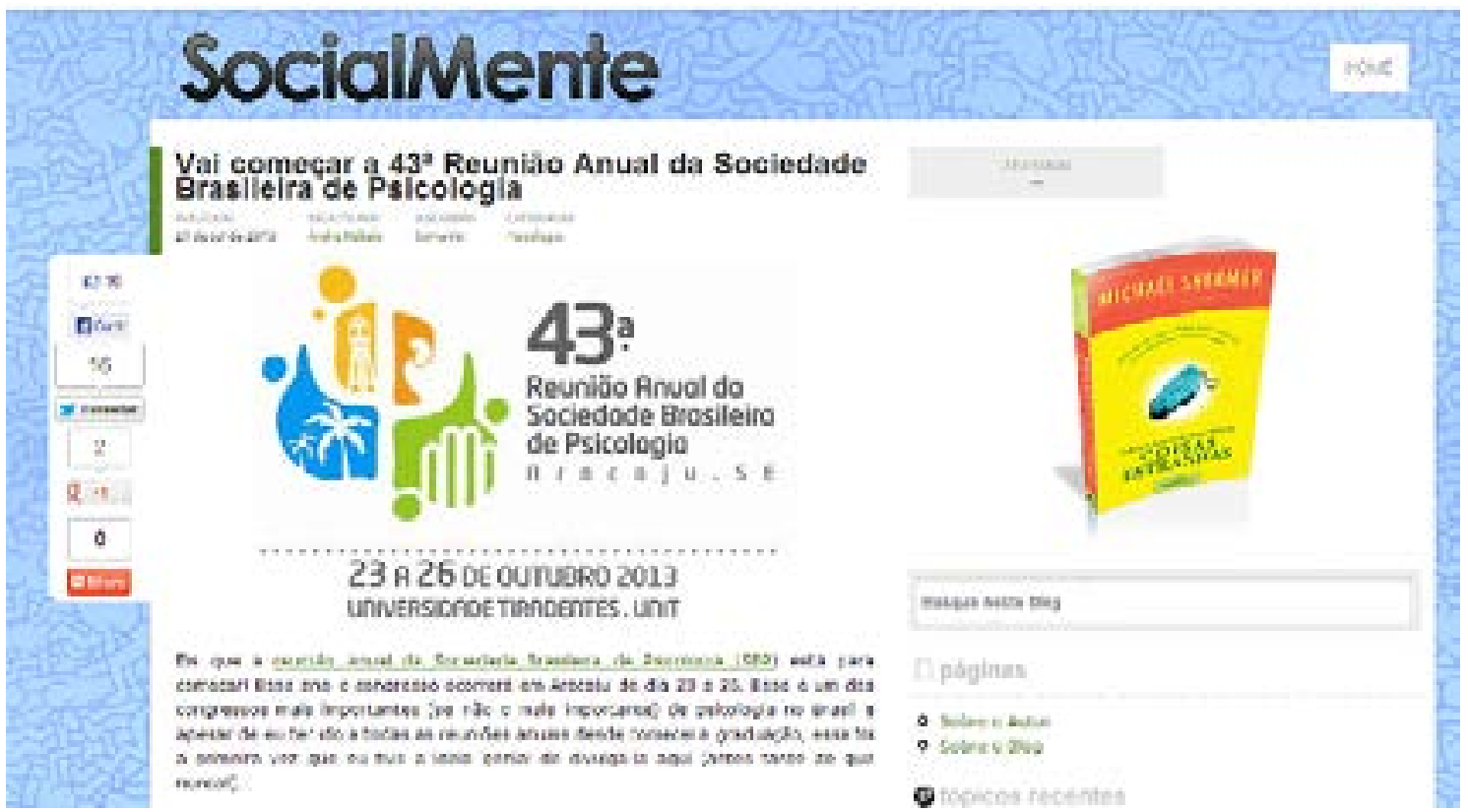

Fonte: http://scienceblogs.com.br/socialmente/2013/10/vai-comecar-a-43a-reuniao-anual-dasociedade-brasileira-de-psicologia/.

\section{Estratégias de envolvimento}

\section{Agenda/vitrine}

A subcategoria de agenda/vitrine tem como função dar visibilidade ao cientista blogueiro ao servir de repositório de documentos, de atividades suas e de seu grupo de pesquisa ou alunos. A forma de registro é informativa que deixa poucas marcas subjetivas no texto. No entanto, a classificamos como categoria Cientista blogueiro protagonista justamente por posicionar o enunciador no centro do enunciado. Entram nessa categoria posts que reproduzem conteúdos midiáticos nos quais os cientistas blogueiros são entrevistados, palestras e aulas ministradas pelo blogueiro, participação em eventos e artigos publicados pelo seu grupo de pesquisa e projetos de financiamentos de pesquisa. Nestes casos, abre-se espaços de autopromoção de divulgação das próprias atividades científicas e acadêmicas do blogueiro (figura 3): 
- Figura 3: Post exemplifica subcategoria de agenda/vitrine

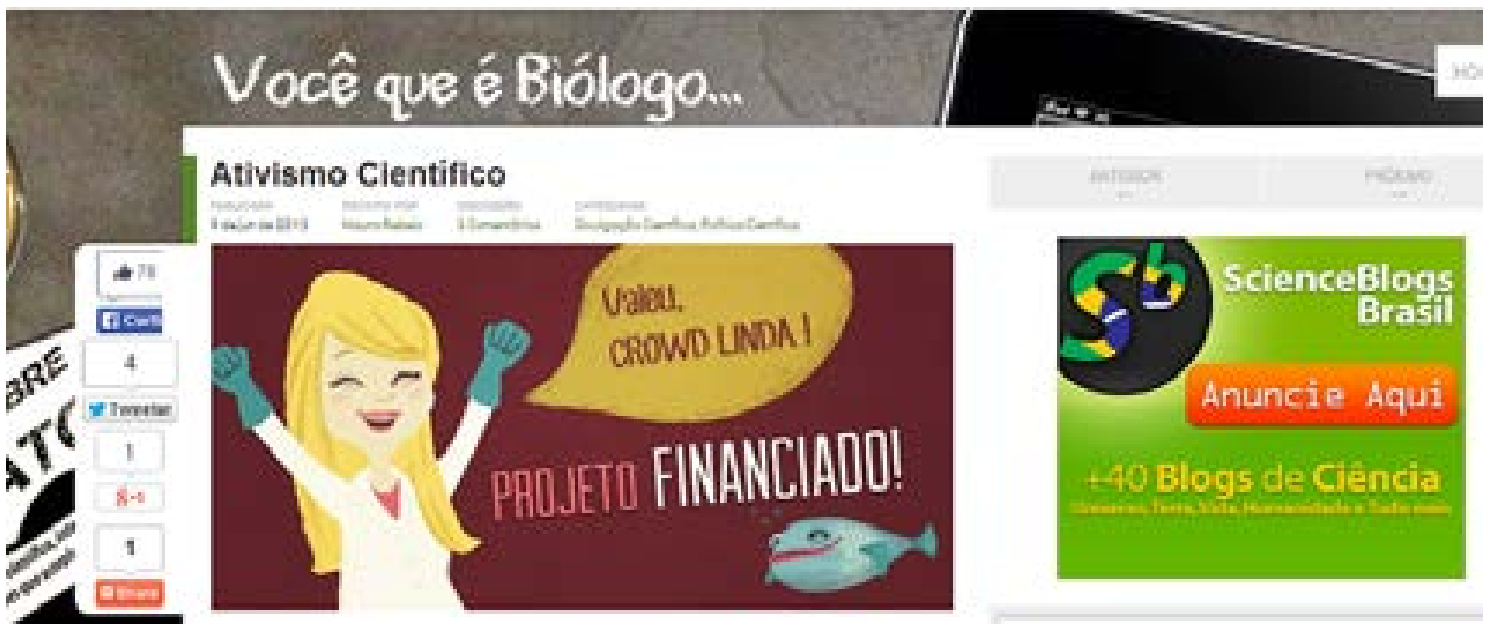

Fonte: <http://scienceblogs.com.br/vqeb/2013/06/ativismo-cientifico/>

Os cientistas blogueiros divulgam também suas participações em congressos e outros eventos e seus livros publicados. No blog "Carnet de Notes", 18 dos 35 posts se encaixam nesse perfil, trazendo informações sobre os eventos em que o cientista blogueiro participou ou participará, além de textos seus publicados em revistas. Neste caso, os blogs se configuram como espaços de visibilidade do pesquisador diante da comunidade científica.

Os blogs servem como vitrines para o pesquisador também em posts destinados a angariar financiamentos de projetos de pesquisa, como é o caso do crowdfunding. A iniciativa é explorada por alguns blogs do corpus, como o "SynbioBrasil" e o “Você que é biólogo...." No blog “Você que é biólogo..., o projeto de financiamento de pesquisa, divulgado em abril de 2013 por meio de um site e de uma página no facebook, teve mais de 350 doadores e conseguiu arrecadar mais de $\mathrm{R} \$ 40.000$ em 60 dias. A iniciativa foi a primeira experiência brasileira de crowdfunding científico e foi divulgada também em jornais e revistas de grande circulação, como os jornais O Globo e Estado de São Paulo e as revistas Ciência Hoje, Galileu e Superinteressante.

\section{Crítica}

A subcategoria crítica abrange posts que tem a função de criticar o funcionamento do sistema científico brasileiro, educativo ou as pesquisas científicas. Para isso, ele utiliza-se de registros opinativos, que moldam posts com intensa tomada de posição do blogueiro. $O$ enunciador molda-se como um sujeito com um estatuto institucional no campo científico que discorre sobre a estrutura econômica e política científica. O registro opinativo aparece, por 
exemplo, na adjetivação e na utilização de outras marcas subjetivas nos temas desenvolvidos pelo blogueiro.

Há blogs que possuem uma quantidade significativa de posts opinativos sobre o sistema científico, os quais são marcados um viés político-ideológico, como os blogs "Neurocientista de Plantão", "Ciência Brasil" e "Blog do Mércio". O primeiro defende a profissionalização do cientista, o segundo trata de denúncias sobre plágio e fraudes científicas e o terceiro assume-se como defensor das comunidades indígenas. Esses blogs são escritos por pesquisadores inseridos em atividades políticas e tornam-se ferramentas para eles defenderem suas causas e exporem sua visão de mundo na rede. Nesses posts, os cientistas atuam como comentadores sobre o sistema científico e a ciência, fazendo críticas e ponderações sobre esses temas.

Outros pesquisadores também utilizam o blog como espaço de desabafos e críticas ao funcionamento do sistema científico. Os blogs se tornam, então, lugares de debates sobre políticas científicas e outros assuntos que impactam diretamente na atividade de pesquisa no Brasil. Há posts que discorrem sobre a falta de estrutura de pesquisa no país, a qualidade nas pesquisas nacionais, entre outros temas. Na figura 4, por exemplo, o cientista blogueiro critica a falta de discussões sobre a política de acesso aberto na comunidade científica brasileira, tema que já vem sendo debatido em outros países.

Figura 4: Post de blog sobre acesso aberto no Brasil

$\mathbf{S}^{b}$ scienceBlogs"

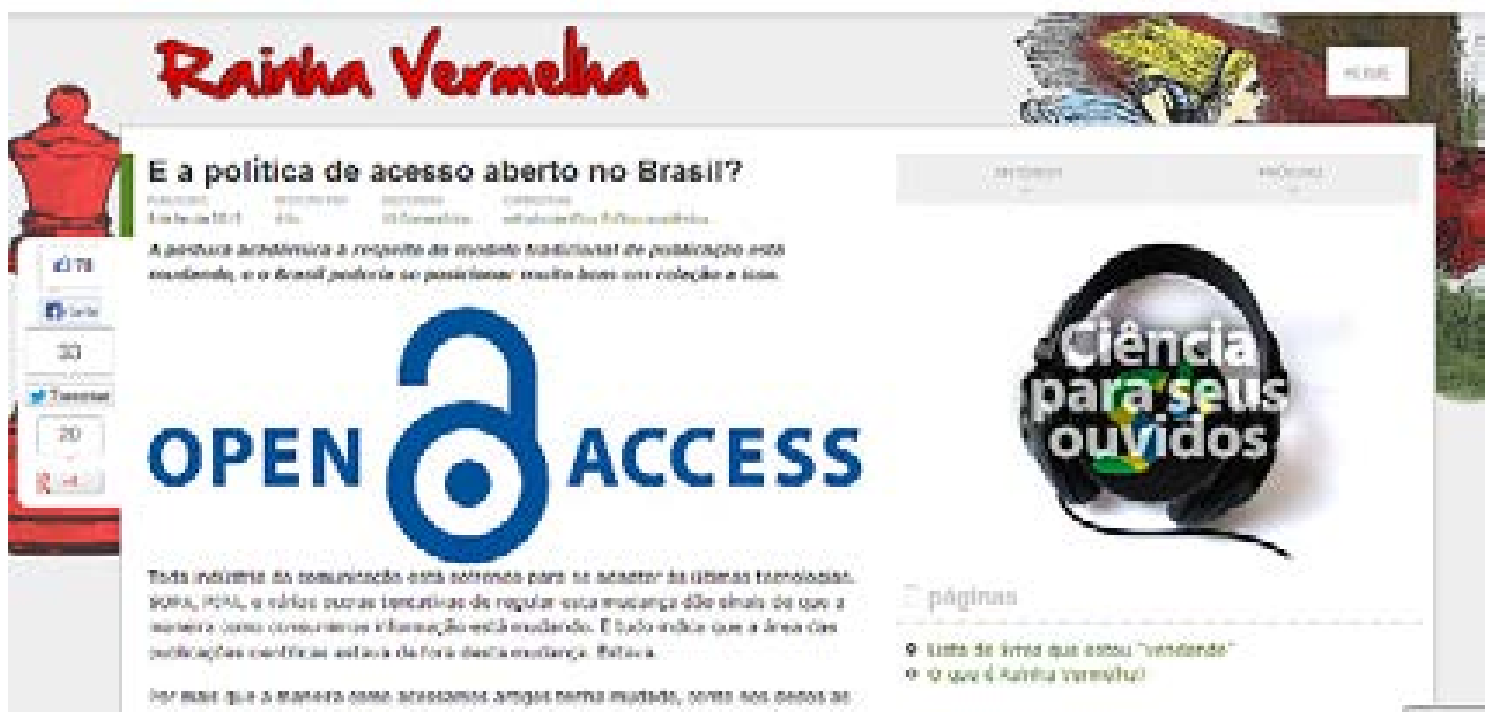

Fonte: <http://scienceblogs.com.br/rainha/2012/02/acesso-aberto/> 
Os blogueiros se assumem, nesse caso, como ativistas em defesa da qualidade da ciência e da divulgação científica. Nos blogs "Ciência Brasil" e "Ecce Medicus", o ativismo dos cientistas pode ser percebido nos posts que desmascaram o esquema de fraudes de quatro revistas científicas brasileiras da área médica, que se utilizavam de diversas artimanhas para burlar o fator de impacto do Journal Citation Reports (JCR). O cientista blogueiro do "Ciência Brasil" recebeu informações de uma fonte sobre o esquema e começou a divulgá-lo no blog a partir de junho de 2013. Segundo ele, o caso, que levou à suspensão das revistas, não recebeu atenção da mídia brasileira, sendo abordado apenas pelos dois blogs. Mais tarde, o assunto também foi tratado em edição da revista Nature.

\section{Diário}

A subcategoria diário trata de textos que procuram refletir sobre a vida em laboratório e outras questões relacionadas à prática científica ou à ciência. Ela diferencia-se da categoria crítica devido ao estatuto do cientista blogueiro que, ao invés de definir-se por meio do seu estatuto institucional, constróise de maneira individual, como sujeito pesquisador. Por meio dessa posição, ele escreve textos sobre seu cotidiano de pesquisa, refletindo sobre o ofício de cientista. Os enunciados assemelham-se ao diário pessoal, conceituado pelo Aurélio on-line como um "livro de anotações contendo a narrativa diária de experiências pessoais". Aqui, a experiência pessoal está necessariamente implicada na reflexão do blogueiro sobre os temas.

Os textos destinados a mostrar as rotinas de laboratórios são escritos numa linguagem informal e relatam experiências de pesquisas do cientista blogueiro, como o fracasso com experimentos, os desafios do mestrado e do doutorado e da escrita acadêmica e o teste de novas técnicas laboratoriais. Algumas vezes, os blogueiros publicam fotos de seu ambiente de trabalho e deles próprios trabalhando, mostrando a rotina do seu laboratório e o ofício de cientista (figura 5).

Além de escrever sobre as atividades científicas desenvolvidas dentro do laboratório, alguns posts dessa subcategoria tratam da prática de divulgação científica, nos quais o cientista blogueiro reflete sobre os motivos de se blogar ou de se realizar outras atividades de DC. A apresentação ao leitor de aspectos do seu cotidiano de trabalho ou das reflexões sobre suas atividades aproxima-o da realidade do cientista, do seu laboratório e das atividades que ele desenvolve. 
- Figura 5: Post mostra rotina do blogueiro em laboratório

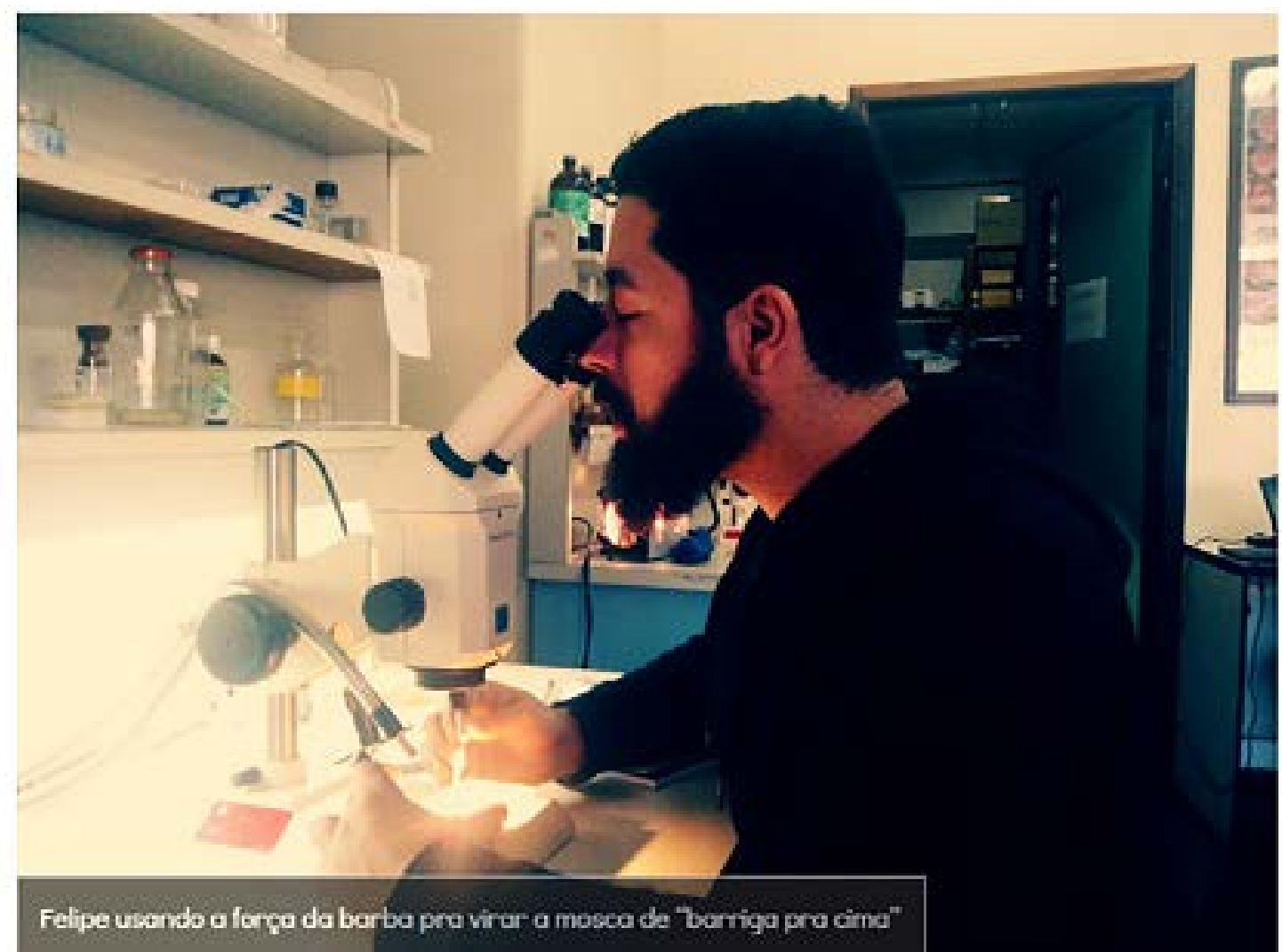

Fonte: <http://scienceblogs.com.br/cronicamoscas/?s=aprndendo+a+dar+baile+em+mosca >

\section{Pessoal}

Por fim, a última subcategoria abrange textos sobre assuntos não científicos, que não possuem relação com a prática profissional do blogueiro e que retratam aspectos da realidade e eventos sociais vistos pela ótica do cientista blogueiro. Assim como na subcategoria anterior, o registro utilizado é o opinativo.

A subcategoria pessoal abrange a maior quantidade de posts (34\%) se comparada a outras categorias, o que não deixa de ser surpreendente se considerarmos que a temática central dos blogs é ciência. Essa quantidade expressiva deve-se, principalmente, ao conteúdo do blog "Ciência Brasil", que abarca 593 posts, 45\% do corpus. Esses posts contêm textos político-partidários do cientista blogueiro que não possuem relação direta com ciência. Alguns dos assuntos tratados são o governo do PT, a prova do Enem e o programa brasileiro Mais Médicos. Em muitos posts, o cientista blogueiro comenta e opina sobre assuntos recentemente discutidos nas mídias sociais e nas mídias tradicionais, como foi o caso das mobilizações e protestos em várias cidades brasileiras de 
junho de 2013. Na figura 6, por exemplo, o cientista blogueiro postou uma ilustração sobre o aumento da tarifa das passagens de ônibus, motivo dos protestos.

- Figura 6: Post representa subcategoria pessoal
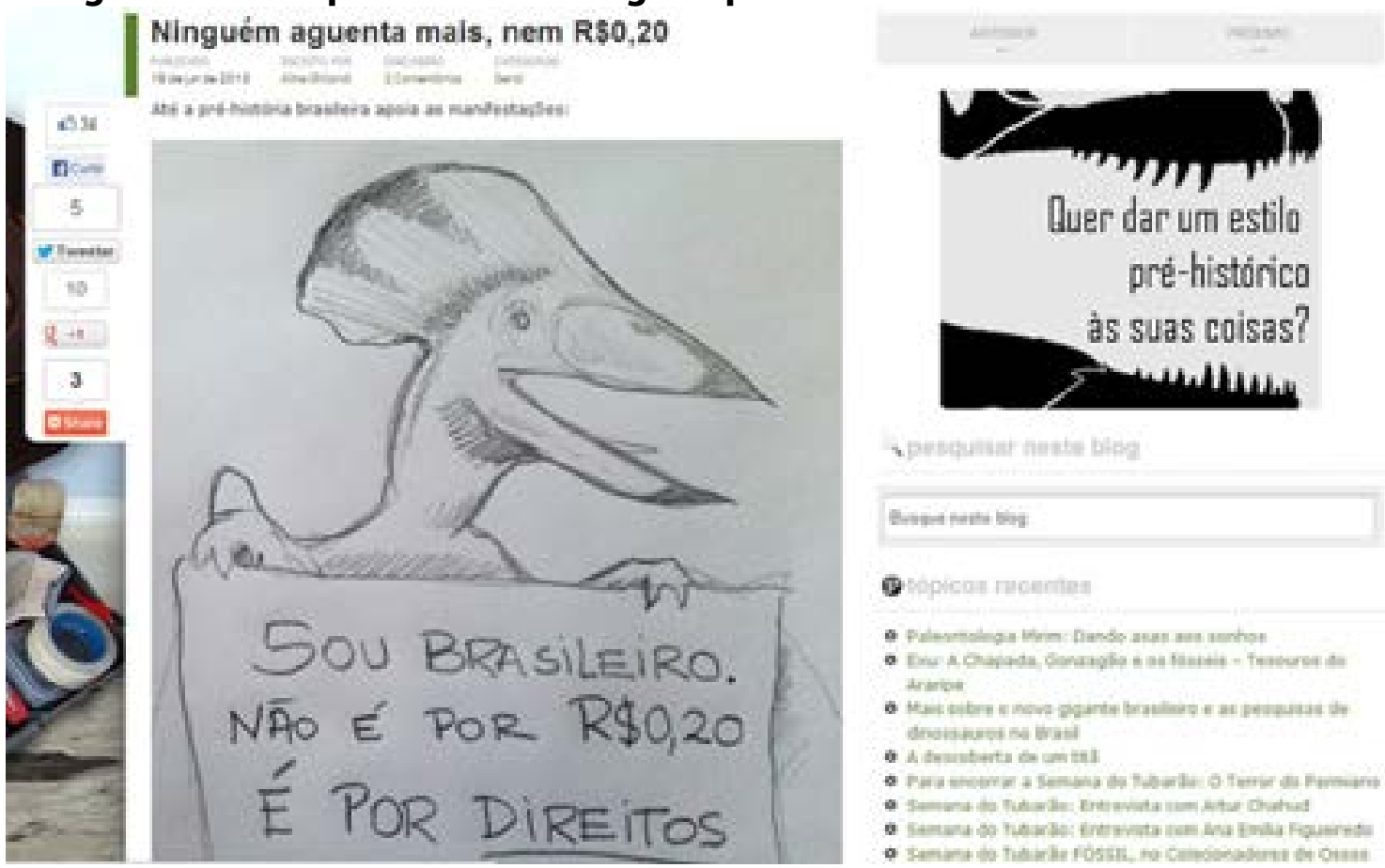

Fonte: $<$ http://scienceblogs.com.br/colecionadores/2013/06/ninquem-aquenta-mais-nem-r020/.>

Os conteúdos não científicos presentes nos blogs fazem emergir o perfil de um cientista que também é cidadão, pois contêm as impressões do cientista blogueiro sobre a sua realidade brasileira. Abre-se espaço para a construção de um cientista que não se detém apenas na sua especialidade, mas que também comenta e opina sobre assuntos diversos.

\section{Algumas considerações}

A análise das materialidades discursivas dos blogs possibilitou descrevermos de modo mais específico as suas funções comunicativas e usos pelos cientistas blogueiros. Assim, antes de termos categorias gerais de funções como"escrita","atualizaçãoe memória"e "disseminação de informação", estudadas por Kjellberg (2010), delineamos funções comunicativas mais detalhadas dessas ferramentas no campo científico, como divulgação de pesquisas científicas e informações sobre ciência, anúncio de eventos científicos, crítica ao sistema científico e reflexão sobre a vida de laboratório. Essas subcategorias ocorrem 
em diferentes proporções e de maneira dispersa no corpus, mas não existe um blog que comporte somente uma categoria.

As subcategorias que trazem lados mais opinativos do cientista blogueiro, como a crítica ao sistema científico e a reflexão sobre a vida em laboratório - por meio de marcas discursivas da expressão do self - podem representar outros modos de construção da imagem do cientista, que aparece como sujeito que opina e reflete sobre a práxis científica. Essa posição acaba por produzir algumas transformações na própria relação entre cientistas e estrutura científica, já que o primeiro se assume como sujeito capaz de colocar a atividade científica sobre a lupa de suas reflexões.

$\mathrm{Na}$ análise quantitativa, percebe-se uma tendência de os blogs escritos por pesquisadores seguirem uma escrita informal e tons pessoais e reflexivos, por meio da adoção de estratégias de envolvimento e da conformação do cientista blogueiro como protagonista da narrativa. Esses posts, que muitas vezes recorrem a estratégias de humor da cultura popular da internet, agregamse ao universo formal e informativo das notícias sobre ciência. Essa mistura de conteúdos acaba por configurar os blogs como espaços heterogêneos, nos quais o cientista assume funções e registros enunciativos de acordo com a sua necessidade comunicacional.

\section{Referências}

BUENO, Wilson da Costa. Jornalismo cientifico: revisitando o conceito. In: Victor, C.; Caldas, G.; Bortoleiro, S (Org.). Jornalismo científico e desenvolvimento sustentável. São Paulo: All Print, p.157-78, 2009.

CALVO HERNANDO, Manuel. Periodismo Científico. Madrid, Editorial Paraninfo. 1992.

CHARAUDEAU, Patrick. Le dialogue dans un modèle de discours. Cahiers de Linguistique Française, n.17, Université de Genève, Suisse, 1995. Disponível em: <http://www.patrick-charaudeau.com/Le-dialogue-dans-un-modele-de. html>. Acesso em: 3 out. 2014.

FAGUNDES, Vanessa. Science blogs: communication, participation and public engagement. In: Anais do 13th International Public Communication of Science and Technology Conference, 5-8 May 2014, Salvador, Brazil.

GOMES, Isaltina. A divulgação científica em Ciência Hoje: características discursivotextuais. 287f. Tese (Doutorado em Lingüística), Universidade Federal de Pernambuco, 2000.

GREGG, Melissa. Feeling Ordinary: Blogging as Conversational Scholarship. Continuum: Journal of Media and Cultural Studies, 20 (2) 147-160, 2006. 
JURDANT, Baudouin. Ecriture, réflexivité, scientificité. Sciences de la société, Toulouse, n.67, p. 131-143, $2006 a$.

. Falar ciência? In: VOGT, Carlos. (org). Cultura Científica: desafios. São Paulo: Editora da Universidade de São Paulo: FAPESP, p. 44-55, $2006 \mathrm{~b}$.

KJELLBERG, Sara. I am a blogging researcher: motivations for blogging in scholarly context. First Monday, Bridgman, v.15, n.8, 2 aug. 2010, Disponível em: $<$ http://firstmonday.org/htbin/cgiwrap/bin/ojs/index.php/fm/article/ view/2962/2580> Acesso em: 31 jan. 2014.

KOUPER, Inna.Science blogs and public engagement with science: practices, challenges, and opportunities. 2010. Disponível em: <http://jcom.sissa.it/archive/09/01/ Jcom0901>(2010)A02. Acesso em: 8 fev. 2013.

MAINGUENEAU, Dominique. Analyser les textes de communication. Paris: Armand Colin, 2014.

PORTO, Cristiane. Impacto da internet na difusão da cultura científica brasileira: as transformações nos veículos e processos de disseminação e divulgação científica. 2010. 97f. Tese (Doutorado) - Programa Multidisciplinar de Pósgraduação em Cultura e Sociedade/Faculdade de Comunicação, Universidade Federal da Bahia, Salvador, 2010.

Recebido em: 09/10/2015

Aceito em: 27/10/2015

Endereço das Autoras:

Isaltina Gomes<isaltina@gmail.com>

Av. Professor Morais Rego, 1235 - Cidade Universitária

50670-901 Recife, PE - Brasil

Natalia Flores < nataliflores@gmail.com>

Av. Professor Morais Rego, 1235 - Cidade Universitária

50670-901 Recife, PE - Brasil 